\title{
Unique versus shared associations between self-reported behavioral addictions and substance use disorders and mental health problems: A commonality analysis in a large sample of young Swiss men
}

\author{
SIMON MARMET ${ }^{1 *}$, JOSEPH STUDER $^{1}$, MATTHIAS WICKI $^{1}$, NICOLAS BERTHOLET $^{1}$, YASSER KHAZAAL KAL $^{1,2}$ and $^{2}$ \\ GERHARD GMEL ${ }^{1,3,4,5}$ \\ ${ }^{1}$ Addiction Medicine, Department of Psychiatry, Lausanne University Hospital and University of Lausanne, Lausanne, Switzerland \\ ${ }^{2}$ Research Centre, University Institute of Mental Health at Montréal, Québec, Canada \\ ${ }^{3}$ Research Department, Addiction Switzerland, Lausanne, Switzerland \\ ${ }^{4}$ Institute for Mental Health Policy Research, Centre for Addiction and Mental Health, Toronto, ON, Canada \\ ${ }^{5}$ Department of Health and Social Sciences, University of the West of England, Bristol, UK
}

(Received: August 6, 2019; revised manuscript received: November 21, 2019; accepted: December 2, 2019)

\begin{abstract}
Background and aims: Behavioral addictions (BAs) and substance use disorders (SUDs) tend to co-occur; both are associated with mental health problems (MHPs). This study aimed to estimate the proportion of variance in the severity of MHPs explained by BAs and SUDs, individually and shared between addictions. Methods: A sample of 5,516 young Swiss men (mean $=25.47$ years old; $S D=1.26$ ) completed a self-reporting questionnaire assessing alcohol, cannabis, and tobacco use disorders, illicit drug use other than cannabis, six BAs (Internet, gaming, smartphone, Internet sex, gambling, and work) and four MHPs (major depression, attention-deficit hyperactivity disorder, social anxiety disorder, and borderline personality disorder). Commonality analysis was used to decompose the variance in the severity of MHPs explained $\left(R^{2}\right)$ by BAs and SUDs into independent commonality coefficients. These were calculated for unique BA and SUD contributions and for all types of shared contributions. Results: BAs and SUDs explained between a fifth and a quarter of the variance in severity of MHPs, but individual addictions explained only about half of this explained variance uniquely; the other half was shared between addictions. A greater proportion of variance was explained uniquely or shared within BAs compared to SUDs, especially for social anxiety disorder. Conclusions: The interactions of a broad range of addictions should be considered when investigating their associations with MHPs. BAs explain a larger part of the variance in MHPs than do SUDs and therefore play an important role in their interaction with MHPs.
\end{abstract}

Keywords: behavioral addictions, substance use disorders, mental health, commonality analysis, Switzerland

\section{INTRODUCTION}

Addictive disorders, including behavioral addictions (BAs) and substance use disorders (SUDs), are widespread among young Swiss men (Gmel et al., 2015; Marmet, Studer, Rougemont-Bücking, \& Gmel, 2018). Although BAs and SUDs are known to co-occur (Starcevic \& Khazaal, 2017; Sussman, Lisha, \& Griffiths, 2011), there are few estimates of the prevalence of these co-occurrences (Konkolÿ Thege, Hodgins, \& Wild, 2016; Schluter, Hodgins, Wolfe, \& Wild, 2018; Sussman et al., 2011), and little is known about how the co-occurrence of these addictions is associated with mental health problems (MHPs).

This study investigated what proportion of variance in the severity of four MHPs - social anxiety disorder (SAD), major depression (MD), adult attention-deficit hyperactivity disorder (ADHD), and borderline personality disorder (BPD) - could be explained by BAs and SUDs individually, respectively, shared between addictions. We considered a broad range of SUDs (alcohol, cannabis, tobacco use disorders, and illicit drug use other than cannabis) and BAs
(Internet, gaming, smartphone, Internet sex, gambling, and work), and for the ease of reading, we use the term addiction to refer to all of them.

Debate continues about whether and how BAs should be conceptualized (Aarseth et al., 2017; Kardefelt-Winther et al., 2017; King et al., 2018; Vaccaro \& Potenza, 2019). Gambling disorder is the only BA currently recognized in the fifth edition of the Diagnostic and Statistical Manual of Mental Disorders (DSM-5) and 11th edition of the International Classification of Diseases (ICD-11). The DSM-5's appendix (American Psychiatric Association, 2013) mentions Internet gaming disorder as a condition for future study, and gaming disorder will be included in the ICD-11 (Aarseth et al., 2017). Other BAs, such as to cybersex (Franc et al., 2018; Varfi et al., 2019) or

\footnotetext{
* Corresponding author: Simon Marmet; Addiction Medicine, Department of Psychiatry, Lausanne University Hospital and University of Lausanne, Rue du Bugnon 23, CH-1011 Lausanne, Switzerland; Phone: +41 2131418 97; Fax: +41 2131405 62; E-mail: simon.marmet@chuv.ch
}

This is an open-access article distributed under the terms of the Creative Commons Attribution-NonCommercial 4.0 International License, which permits unrestricted use, distribution, and reproduction in any medium for non-commercial purposes, provided the original author and source are credited, a link to the CC License is provided, and changes - if any - are indicated. 
smartphone use (Panova \& Carbonell, 2018), are nevertheless receiving increasing interest due to concerns about the possible consequences of such disorders (Dong \& Potenza, 2016; Paik et al., 2019).

Few studies have assessed the links between BAs and MHPs (Andreassen et al., 2016; Starcevic \& Khazaal, 2017), and most were carried out on self-selected samples, reducing any possibility of generalizing their findings (Andreassen et al., 2016) due to the risk of an overrepresentation of people highly caught up in the behaviors screened for (Khazaal et al., 2014). In a global context of increasing technology use by young people (Dufour et al., 2016) and growing concerns about related BAs, a better understanding of the possible interactions between BAs, SUDs, and MHPs appears crucial (Grant, Potenza, Weinstein, \& Gorelick, 2010; Starcevic, 2016).

\section{Co-occurrence of addictions}

Many studies have demonstrated that addictions often co-occur. A systematic review of 83 studies (Sussman et al., 2011) found that, on average, $23 \%$ of individuals with one addiction also had a second addiction, with estimates for co-occurrences between 11 addictions ranging from $10 \%$ to $50 \%$ (e.g., $50 \%$ between tobacco and alcohol addiction, 20\% between gambling and alcohol addiction, or $10 \%$ between Internet and work addiction). Sussman et al. (2014) studied the occurrence and co-occurrence of the same 11 addictions in a sample of 717 former high-school students (around 20 years old) using a matrix measure (the same set of questions per addiction): $61.5 \%$ reported at least one addiction in the past 30 days, and $37.7 \%$ reported at least two co-occurring addictions. In a Canadian general population sample, $50.8 \%$ of respondents reported at least one addiction problem, $13.1 \%$ reported two, and $7.9 \%$ reported three or more. However, the addiction problems were assessed with a single question asking whether they had a problem with each respective substance/behavior (Konkolÿ Thege et al., 2016).

Multiple explanations for the co-occurrence of different addictions have been suggested. Some authors suggest that different addictions have considerable overlap in etiological, phenomenological, and clinical presentations and may therefore be best understood as different expressions of the same underlying disorder (Kim \& Hodgins, 2018; Marmet et al., 2018; Shaffer et al., 2004). Other possible mechanisms are cross-reinforcement and cross-tolerance, which have been demonstrated between alcohol-use disorder (AUD) and tobacco-use disorder (TUD). Alcohol and tobacco were found to potentiate each other's rewarding effect (cross-reinforcement), and nicotine was found to attenuate the sedative and intoxicating effects of alcohol consumption (cross-tolerance; Adams, 2017). Common genetic vulnerabilities have also been identified for alcohol and nicotine dependence (True et al., 1999) as well as for alcohol dependence and pathological gambling (Slutske et al., 2000; Slutske, Ellingson, Richmond-Rakerd, Zhu, \& Martin, 2013). Although there is some evidence for genetic parallels between substance and non-substance addictions, research in this domain is still at an early stage (Grant et al., 2010; Leeman \& Potenza, 2013).

\section{Addictions and MHPs}

Rates of co-occurrence between SUDs and MHPs are high (Dom \& Moggi, 2016) and the literature covers this in depth (Lieb, 2015; Morisano, Babor, \& Robaina, 2014; Torrens \& Rossi, 2015; van Emmerik-van Oortmerssen, Konstenius, \& Schoevers, 2015; Walter, 2015). A recent review (Starcevic \& Khazaal, 2017) also found that BAs and MHPs often co-occur, but it also noted that most of the studies included suffered from methodological limitations. Although there is solid evidence for associations between addictions and MHPs, few studies have investigated whether the co-occurrence of different addictions (especially BAs) is associated with MHPs. Multiple studies have found that polysubstance dependence (Skinstad \& Swain, 2001) and polysubstance use (Andreas, Lauritzen, \& Nordfjærn, 2015; Bhalla, Stefanovics, \& Rosenheck, 2017; Brook, Zhang, Rubenstone, Primack, \& Brook, 2016; Connor et al., 2013; Moss, Goldstein, Chen, \& Yi, 2015; Smith, Farrell, Bunting, Houston, \& Shevlin, 2011; White et al., 2013) are associated with increased rates of psychiatric comorbidity. A study using the US national Veterans Health Administration register of 472,642 veterans with at least one SUD found that $26.8 \%$ of them had at least two SUDs (Bhalla et al., 2017) and that having two or more SUDs was associated with more medical and psychiatric disorders. Using the same sample, MacLean, Sofuoglu, and Rosenheck (2018) found that combined AUD and TUD was associated with higher prevalence rates of other SUDs (e.g., cocaine use disorder) and schizophrenia. Hence, the co-occurrence of SUDs is common and associated with increased risks of other mental disorders.

In a study of 385 treatment-seeking pathological gamblers, tobacco use was found to be associated with more severe gambling problems, as were MHPs (Odlaug, Stinchfield, Golberstein, \& Grant, 2013). To the best of our knowledge, that was the only study so far to have investigated co-occurring BAs and SUDs and their associations with MHPs.

\section{Aims}

Although there is limited evidence about co-occurring SUDs and how they are associated with MHPs, there is an almost total lack of research about co-occurring BAs and co-occurring SUDs and BAs, and how they are associated with MHPs. A better understanding and increased awareness of the interactions between addictions and MHPs could help significantly in the treatment and prevention of addictive disorders and MHPs. Refining treatments to simultaneously improve both types of disorders seems particularly challenging (Chow, Wieman, Cichocki, Qvicklund, \& Hiersteiner, 2013; Lenz, Henesy, \& Callender, 2016; Penzenstadler, Kolly, Rothen, Khazaal, \& Kramer, 2018), although holistic treatment approaches have shown some promising results, for example, integrated treatment approaches taking into account addictions and MHPs (Dom \& Moggi, 2015; Morisano et al., 2014; van Wamel, van Rooijen, \& Kroon, 2015). In addition, such findings could inform discussions about whether BAs should be considered 
public health problems of equal significance to SUDs and MHPs (Aarseth et al., 2017; Kardefelt-Winther et al., 2017).

Therefore, this paper first aims to describe patterns of co-occurring addictions in a large non-selectively sampled cohort of young Swiss men. Second, it investigates how co-occurring addictions are associated with the severity of four MHPs. Given the high rates of co-occurrence between addictions, it is often difficult to say how any one addiction is associated with an MHP; it could be associated entirely independently, or its association with an MHP may be more or less completely shared with other SUDs or BAs. Thus, third, we try to better understand the interactions between addictions and MHPs using commonality analysis (CA). CA describes to what extent the variance in the severity of four MHPs explained by addictions is shared between addictions and estimates which proportion of the variance explained is unique to any of the 10 addictions, shared within SUDs, shared within BAs, and shared jointly between SUDs and BAs.

\section{METHODS}

\section{Sample}

The sample consisted of young men from the Cohort Study on Substance Use Risk Factors (C-SURF; www.c-surf.ch), a cohort study designed to examine substance use patterns and related factors in Switzerland (for an overview, see Gmel et al., 2015; Studer et al., 2013). Enrollment for the baseline assessment took place during the recruitment procedure for military service in Switzerland, at three of the six national military recruitment centers, located in Lausanne, Windisch, and Mels and covering 21 of 26 Swiss cantons. The procedure is mandatory for all young Swiss men, meaning that the sample was drawn without a priori selection. Written consent to participate in the study was given by 7,556 young men; 5,987 returned the first questionnaire between September 2010 and March 2012 and 5,516 (of whom 391 had not completed the first questionnaire) returned the third questionnaire between April 2016 and March 2018. This study uses data from the third questionnaire only, when participants were $25.47(S D=1.26)$ years old during questionnaire completion. Study procedures were carried out independently of the military, and the questionnaires were filled out at participants' homes, either online or on paper. Vouchers were given out to thank the young men for participation in the study.

\section{Measures}

All measures for SUDs, BAs, and MHPs used in this study are described in detail in Table 1. We used the presence of SUDs or BAs dichotomously for estimating the co-occurrence of addictions, and continuous severity scores for dominance and $\mathrm{CA}$.

\section{Statistical analyses}

Data preparation and descriptive statistics were conducted using SPSS 25 (Armonk, NY, USA). Multiple imputation using fully conditional specifications for 10 imputed data sets was used to replace missing values for items of the addiction and MHP scales. At least one value was imputed for 201 participants $(3.6 \%)$.

As per the first aim, the co-occurrence of addictions was described by estimating how many participants with any one addiction had at least one of the other nine possible addictions. To test whether an addiction (dichotomously measured as present/absent) occurred more frequently in participants with any other particular addictions, tetrachoric correlations were calculated using Stata 15 (College Station, TX, USA). Spearman's correlations were used to test whether the severities on addiction scales were correlated.

To fulfill the second aim, the prevalence rates of and the scores for the four MHPs were calculated by number of addictions $(0,1,2,3,4$, and 5+). Linear regressions were used to test whether the severity of participants' MHPs increased with the number of their addictions, and logistic regressions were used to test whether the prevalence of MHPs increased as the number of addictions did.

Finally, for the third aim, CA (Nimon \& Oswald, 2013; Ray-Mukherjee et al., 2014; Seibold \& McPhee, 1979) was used to decompose the explained variance $\left(R^{2}\right)$ of the criterion variable (severity of MHP) into $2^{k}-1$ independent commonality coefficients for all the possible combinations of $k$ explanatory variables (the scores of the study's 10 addictions) in a multiple linear regression model. CA allows us to decompose the explained variance of an MHP's severity into the individual contributions of each addiction, and the shared or common contributions for two or more addictions (i.e., explained variance shared between any of the possible combination of addictions). In this study of 10 addictions, CA returns $1,023\left(2^{10}-1\right)$ commonality coefficients. Because interpreting so many coefficients is difficult, we summarized them in two ways. First, the total variance of an MHP explained by one particular addiction (i.e., the square of the bivariate correlation between the addiction and the respective MHP) was decomposed into three parts: (a) the unique $R^{2} \mathrm{~s}$, (b) the $R^{2} \mathrm{~s}$ shared with other addictions of the same type (e.g., AUD shared with other SUDs, but not with BAs), and (c) the $R^{2} \mathrm{~s}$ shared with addictions of the other type (e.g., AUD shared with any BA). In a second step, we summed the unique contribution $\left(R^{2}\right)$ for SUDs and BAs, the sum of the $R^{2}$ shared within the SUD category and within the BA category, and the sum of the $R^{2}$ shared between SUDs and BAs. As commonality coefficients are independent and add up to the total $R^{2}$ of a regression model, commonality coefficients can simply be added up.

As a complement to the CA, each addiction's relative contribution to the four MHPs was estimated using general dominance analysis. This partitions a multiple regression model's total $R^{2}$ into general dominance weights across the 10 addictions, using the severity of an MHP as the criterion variable. A general dominance weight reflects a variable's importance in the regression model, and it is based on the weighted averages of all the possible subset regressions given a set of independent variables. Thus, in the present analysis, general dominance analysis produced dominance weights for the 10 addictions that add up to the total $R^{2}$ of all the addictions in the model [see Nimon and Oswald's (2013) 
Variance of mental health problems explained by addictions

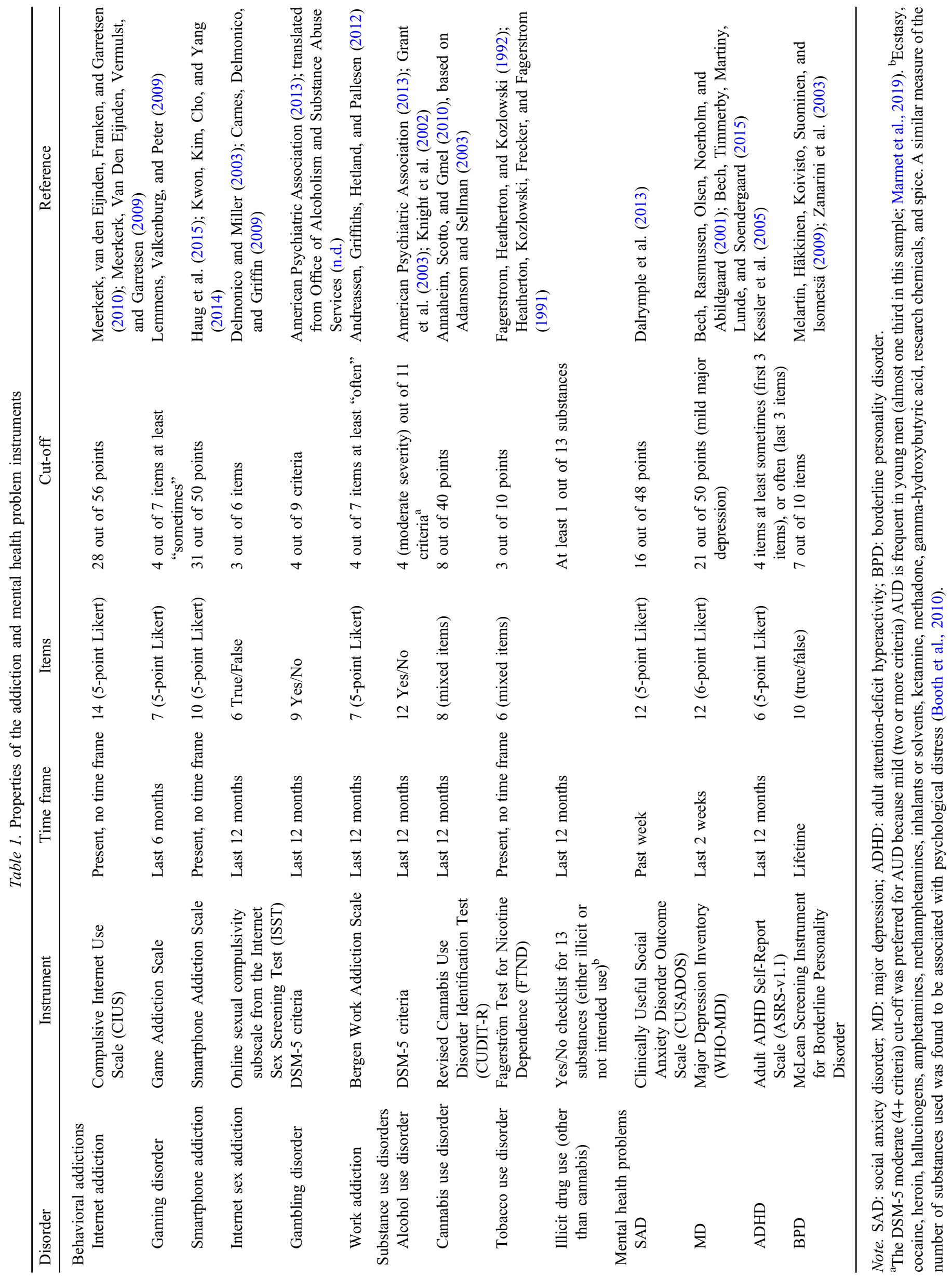


study for a more comprehensive introduction to general dominance analysis]. Dominance and commonality coefficients were computed using the yhat software package (Nimon \& Oswald, 2013) in R software (R Core Team, 2013), and 95\% confidence intervals (CI) for individual coefficients were bootstrapped (with 1,000 samples drawn per imputation) using the function provided in the yhat software package (Nimon \& Oswald, 2013). Because there is no function implemented for bootstrapping the CIs for the sums of commonality coefficients, these were approximated using the formula for the CI of $R^{2}$ described by Cohen, Cohen, West, and Aiken (2003).

\section{Ethics}

The research protocol for C-SURF was approved by the Human Research Ethics Committee of the Canton Vaud (protocol no. 15/07). All participants were informed about the study and provided written informed consent. Participants were allowed to end their participation in the study at any time.

\section{RESULTS}

Table 2 shows descriptive statistics, means, and prevalence rates for SUDs and BAs. Overall, $47.1 \%$ of the sample had at

Table 2. Descriptive statistics, mean severity, and prevalence rates of addictions and mental health problems

\begin{tabular}{|c|c|c|c|}
\hline & Mean & $S D$ & $\begin{array}{c}\text { Prevalence } \\
(\%)\end{array}$ \\
\hline Age (years) & 25.47 & 1.26 & \\
\hline \multicolumn{4}{|l|}{ Linguistic region } \\
\hline French & & & 57.6 \\
\hline German & & & 42.4 \\
\hline \multicolumn{4}{|l|}{ Behavioral addictions (BAs) } \\
\hline Internet & 9.16 & 8.95 & 4.7 \\
\hline Gaming & 3.26 & 4.25 & 7.0 \\
\hline Smartphone & 8.07 & 7.85 & 8.1 \\
\hline Internet sex & 0.59 & 1.04 & 6.9 \\
\hline Gambling & 0.14 & 0.74 & 1.4 \\
\hline Work & 8.53 & 4.96 & 8.0 \\
\hline \multicolumn{4}{|c|}{ Substance use disorders (SUDs) } \\
\hline Alcohol & 1.24 & 1.61 & 8.8 \\
\hline Cannabis & 1.78 & 4.72 & 8.0 \\
\hline Tobacco & 0.90 & 1.69 & 16.9 \\
\hline $\begin{array}{l}\text { Illicit drug use other than } \\
\text { cannabis }\end{array}$ & 0.28 & 0.93 & 12.4 \\
\hline At least one addiction (SUD & ( BA) & & 47.1 \\
\hline At least two addictions (SU) & or BA) & & 20.9 \\
\hline \multicolumn{4}{|l|}{ Mental health problems } \\
\hline MD & 7.51 & 8.26 & 16.7 \\
\hline ADHD & 8.64 & 7.40 & 7.8 \\
\hline SAD & 6.86 & 4.23 & 7.8 \\
\hline BPD & 1.72 & 2.17 & 4.8 \\
\hline
\end{tabular}

Note. Illicit drugs included ecstasy, cocaine, heroin, hallucinogens, amphetamines, methamphetamines, inhalants or solvents, ketamine, methadone, gamma-hydroxybutyric acid, research chemicals, and spice. MD: major depression; ADHD: attention-deficit hyperactivity disorder (adult); SAD: social anxiety disorder; BPD: borderline personality disorder; $S D$ : standard deviation. least one addiction and $20.9 \%$ had a second addiction (Table 2). Furthermore, there was a high degree of co-occurrence between addictions (Table 3), as well as correlation between addiction severities (Supplementary Table S1), especially among SUDs and among the technological BAs (Internet, gaming, smartphone, and Internet sex).

Having an addiction - and especially having more than one addiction - was associated with considerably higher mean severity of MHPs (Table 4). Overall, the 10 addictions explained between 19.41\% (95\% CI $=15.14$, 23.73; SAD) and $27.39 \%(20.12,34.66$; MD) of the variance in the severity of MHPs (Figure 1; Table 5 for CIs; see Supplementary Tables S2 and S3).

Figure 1 shows the results of the dominance analysis, i.e., which proportion of the explained variance of the severity of an MHP is attributable to each of the 10 addictions. More explained variance was attributable to BAs than to SUDs, especially for SAD, where $94.5 \%$ ( $18.35 \%$ out of $19.41 \%$ ) of the total variance explained by addictions was explained by BAs. The corresponding proportions of explained variances by BAs were $79.2 \%$ for $\mathrm{MD}, 78.1 \%$ for $\mathrm{ADHD}$, and $64.3 \%$ for BPD. Given that there were more BAs than SUDs, their contributions almost matched per addiction for BPD. The highest individual contributions to MHP severity, in terms of general dominance, were work addiction for MD and BPD, and Internet addiction for ADHD and SAD.

As estimated using CA, Figure 2 shows the proportions of explained variance in the severity of MHPs (a) unique to individual addictions, (b) shared within an addiction category (SUD or BA), and (c) the joint share for SUDs and BAs. Between 39.2\% (ADHD) and 51.6\% (MD) of the total explained variance in the severity of MHPs was done so by the 10 addictions taken individually (Figure 2). The overall contributions of addictions taken individually were considerably higher for BAs than for SUDs, especially for SAD, where the variance explained by individual SUDs was very low $[0.32 \%(0.30,0.34)$ out of $2.34 \%(2.23,2.45)$ compared to $7.55 \%(6.60,8.50)$ out of $19.08 \%(14.92,23.24)$ for BAs; Table 5]. Similarly, a greater proportion of the explained variance in severity was shared within BAs than within SUDs. Given that the total contribution of SUDs was lower than that of BAs, the joint share for SUDs and BAs was more relevant for SUDs than for BAs: for SAD, almost all of the contribution of SUDs was jointly shared with BAs $[2.01 \%(1.93,2.08)$ out of $2.34 \%(2.23,2.45)]$. For MD and BPD, about half of the contribution of SUDs was shared with BAs.

Overall, for the four MHPs investigated, a greater share of the variance in severity was explained by BAs, but the degree to which SUDs and BAs contributed across those MHPs varied: for SAD, BAs explained 17.07\% (13.57, $20.57)$, i.e., $7.55 \%+9.52 \%$ out of $19.41 \%(15.14,23.68)$ of the variance (individually or in common with other BAs), with a further $2.01 \%(1.93,2.08)$ being shared with SUDs. However, SUDs explained only $0.33 \%(0.31,0.35)$, i.e., $0.32 \%+0.01 \%$. For BPD, a much greater proportion was explained by SUDs; MD and ADHD were in-between (Table 5; Figure 2).

Supplementary Tables S4-S7 demonstrate the 25 highest commonality coefficients for combinations of the 10 addictions with respect to the MHPs. 
Variance of mental health problems explained by addictions

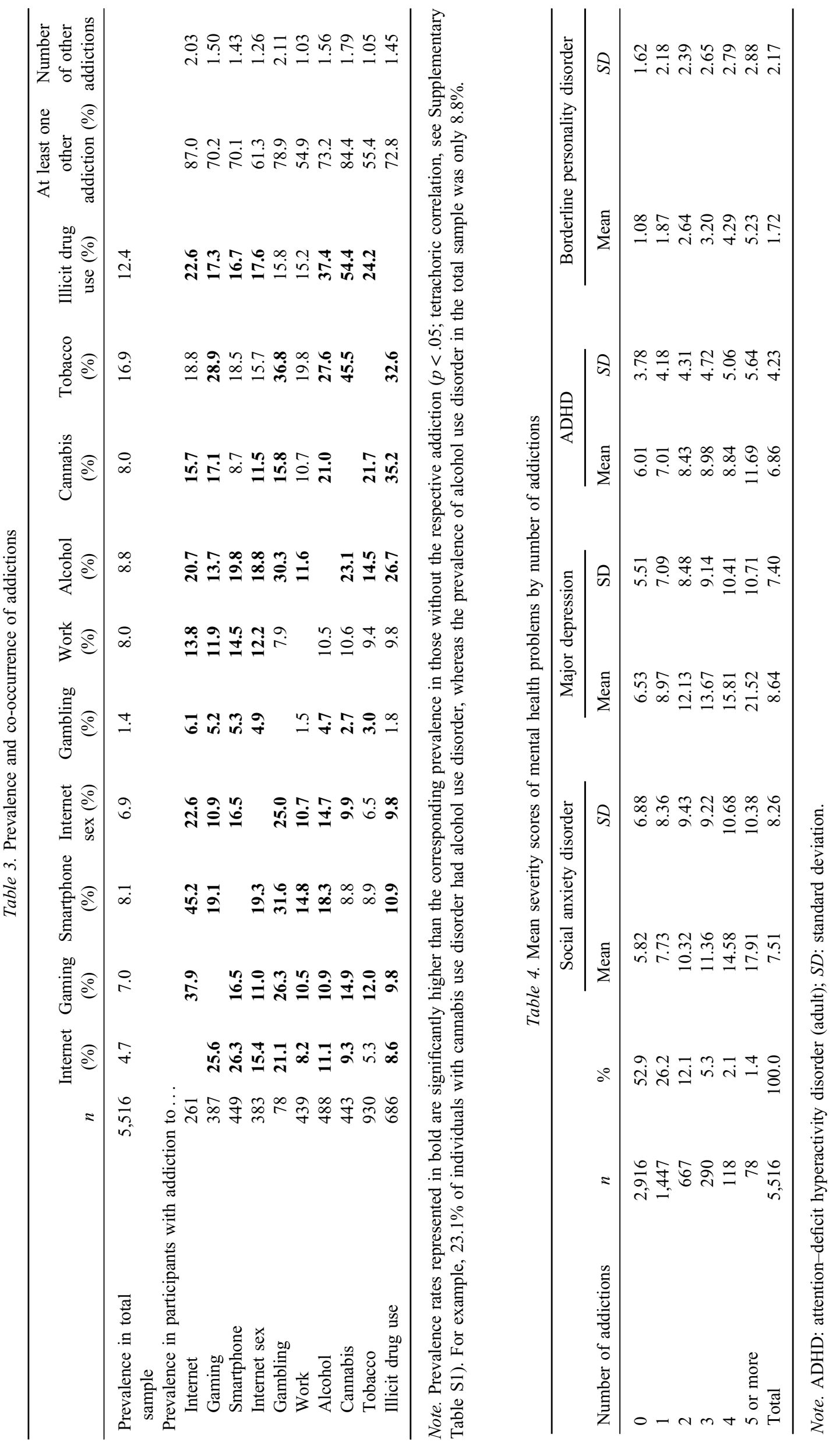


$30 \%$

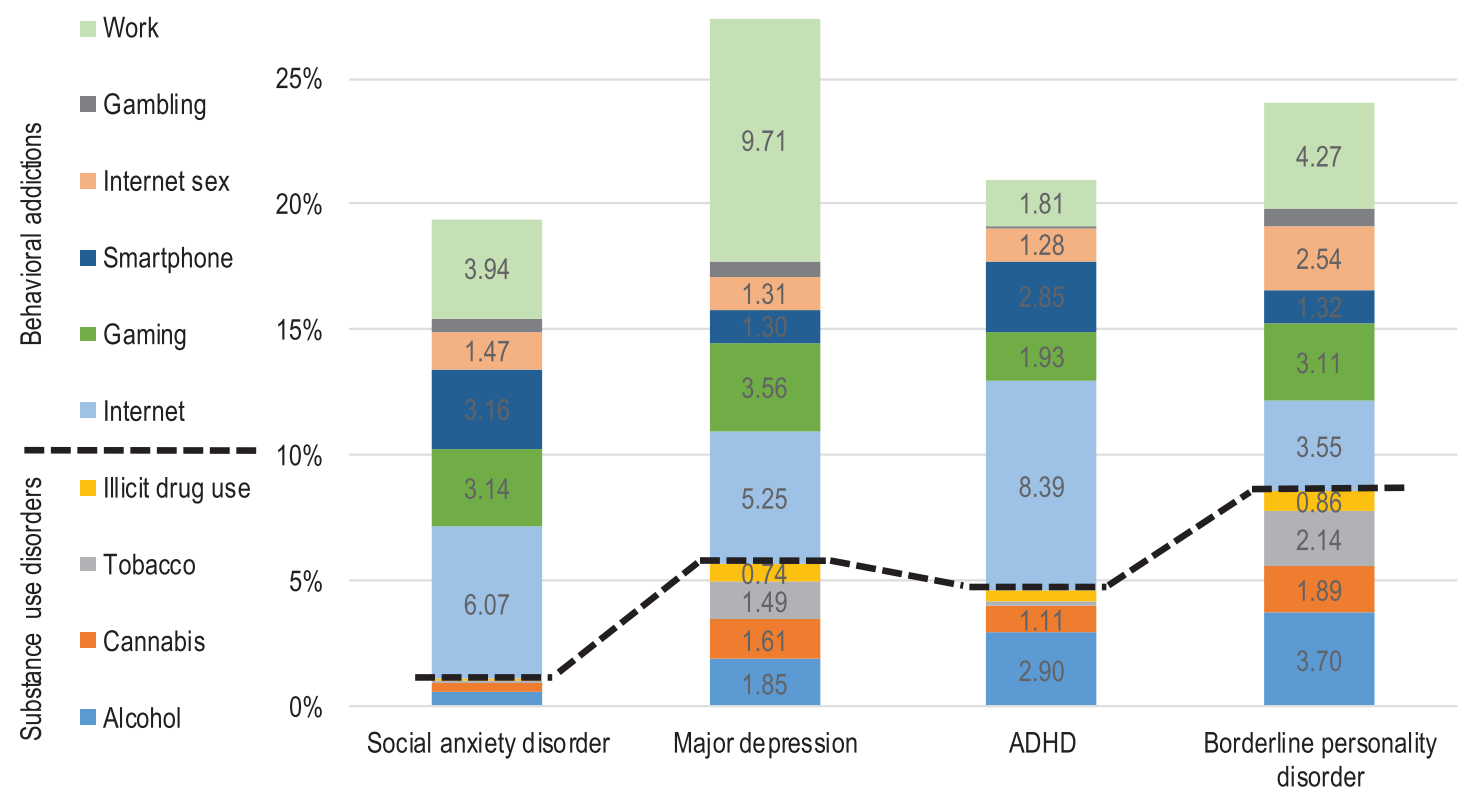

Figure 1. Proportions of general dominance (\% of variance explained) of the 10 addictions on mental health problems. Note. The general dominance coefficients add up to the total $R^{2}$. Labels are percentages of variance explained (not shown for coefficients below $1 \%$ ). Dashed lines separate behavioral addictions from substance use disorders. ADHD: attention-deficit hyperactivity disorder (adult)

\section{DISCUSSION}

\section{Co-occurrence of addictions}

This study analyzed the co-occurrence of six BAs and four SUDs and their associations with the severity of four MHPs in a large non-selective sample of young Swiss men. Overall, $47.1 \%$ of these men had at least one of the 10 SUDs or BAs measured. Almost half of those with at least one addiction also had at least a second addiction, which is in line with earlier literature showing high degrees of co-occurrence (Sussman et al., 2011). There were two main clusters of co-occurrence: between the different technologyrelated BAs (Internet, gaming, smartphone, and Internet sex) and between SUDs (alcohol, cannabis, tobacco, and illicit drugs), but there was also considerable co-occurrence between these two groups of addictions.

In this study, having at least one addiction was associated with greater severity in all four MHPs examined, and these severities increased steeply if more than one addiction was present, showing that co-occurring addictions are strongly associated with the severity of MHPs. That this is true for BAs as well as SUDs extends earlier findings showing that combinations of SUDs (e.g., AUD and TUD) were associated with the presence of MHPs (Bhalla et al., 2017; MacLean et al., 2018; Skinstad \& Swain, 2001).

\section{Variance in the severity of MHPs explained by addictions}

Overall, the 10 addictions accounted for $19.41 \%$ of the explained variance in the severity of SAD, $27.39 \%$ of $\mathrm{MD}$, $20.95 \%$ of ADHD, and $24.04 \%$ of BPD, corresponding to medium or even large ( $\geq 26 \%$ ) effect sizes (Cohen, 1988). Analysis of general dominance showed that more than $90 \%$ of the variance explained by addictions in the severity of
SAD was attributable to BAs. BAs explained more than three quarters of the variance in the severity of MD and ADHD, but considerably less for BPD - about two thirds. Although BAs were important in explaining the variance of all four MHPs, their contribution was more dominant for the internalizing disorders (SAD and MD) than for ADHD and BDP, which are rather externalized and impulse controlrelated disorders.

The individual addiction with the highest association with $\mathrm{SAD}$, as measured by dominance coefficients, was Internet addiction, which involves a wide range of different activities. Associations between SAD and different BAs related to cybersex, social networks, and gaming have been reported repeatedly (Sioni, Burleson, \& Bekerian, 2017; Weinstein et al., 2015; Zlot, Goldstein, Cohen, \& Weinstein, 2018). The core symptoms of SAD (fear and avoidance of social situations; Heeren \& McNally, 2016) lead people with SAD to feel anxious about social interactions, uncomfortable with face-to-face contact, and to avoid feared social situations. The Internet allows social interactions to take place behind a screen or via an avatar that gives people a sense of anonymity (Zlot et al., 2018). This may lead individuals with SAD to increase their social interactions in this context, searching for social connections, approval and reward online instead of via face-to-face, real-world, social connections (Sioni et al., 2017). One may hypothesize that such involvement in Internet-related behaviors might increase the use of such platforms, leading to BAs, and the maintenance or increase in the severity of SAD symptoms due to persistent avoidance of face-to-face social interactions. Furthermore, SAD is associated with cognitive attentional biases related to social stimuli (possibly threatened ones and social comparison ones; Bantin, Stevens, Gerlach, \& Hermann, 2016). Such cognitive biases may impair disengagement from Internet-related social stimuli when 


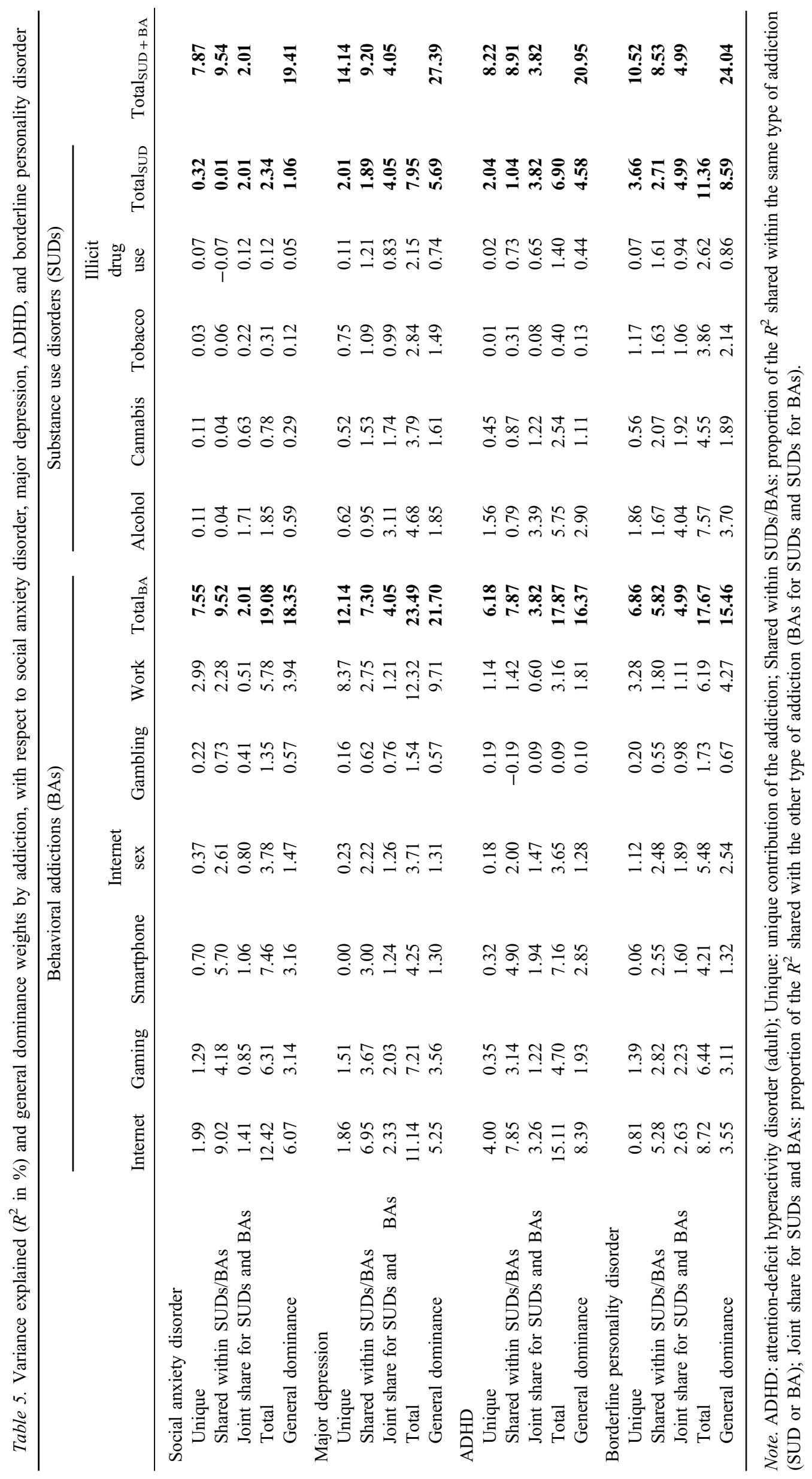




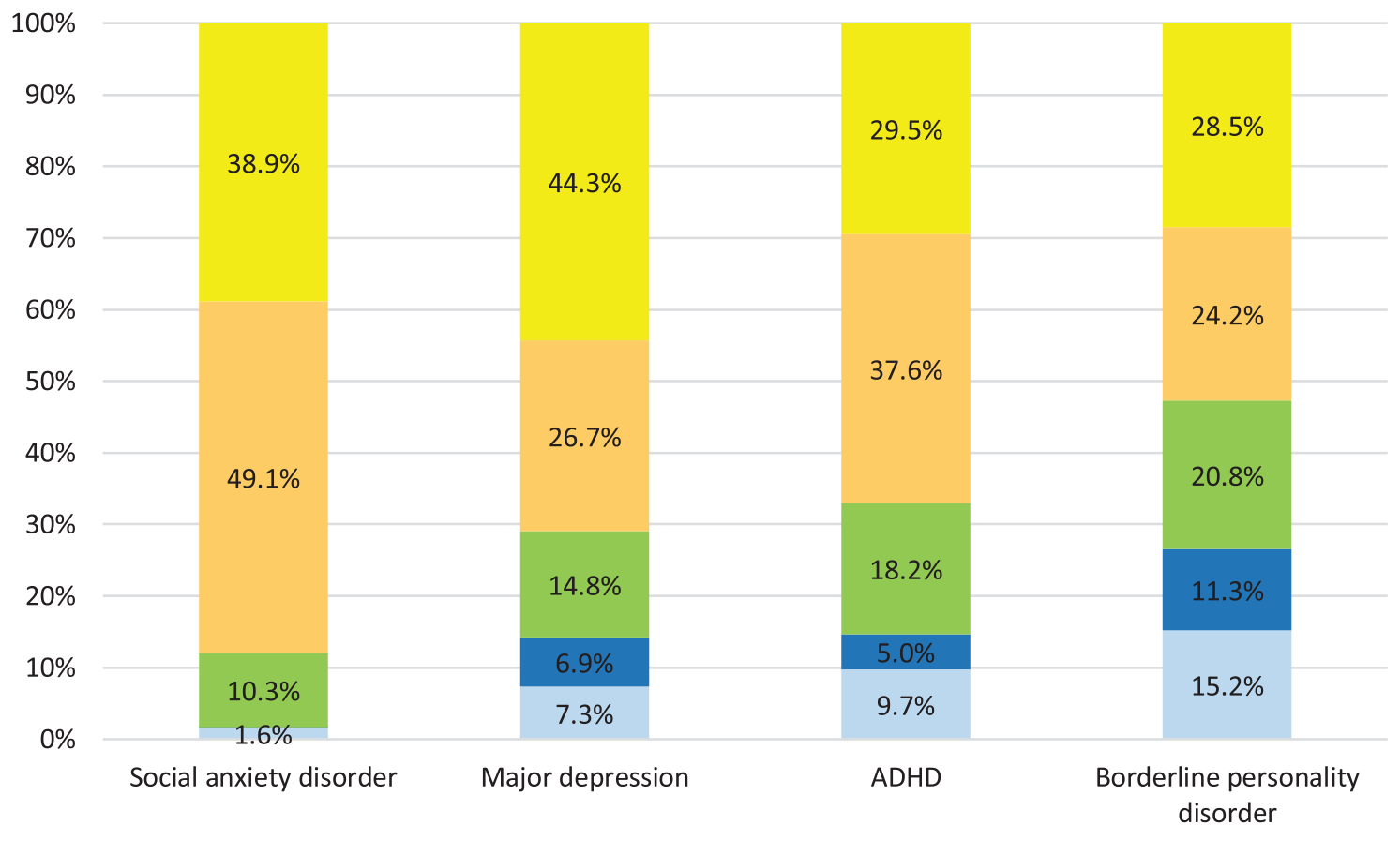

SUD unique $\square$ Shared within SUDs $\square$ Shared between SUDs and BAs $\square$ Shared within BAs $\square$ BA unique

Figure 2. Unique and shared variance of mental health problems explained by substance use disorders, behavioral addictions, and their combination, in \% of total variance explained by addictions. Note. ADHD: attention-deficit hyperactivity disorder (adult)

online and contribute to Internet addiction, which in turn contributes to increasing symptoms of SAD through impaired reassurance mechanisms. Further prospective and laboratory studies are needed to assess such hypotheses.

ADHD's strongest association with an individual addiction was also with Internet addiction. Previous studies have related both components of ADHD (inattention and hyperactivity/impulsivity) to the severity of Internet addiction symptoms (Evren, Evren, Dalbudak, Topcu, \& Kutlu, 2018). One could hypothesize that the relative importance of the association between Internet addiction and ADHD is linked to changes in cognitive functioning induced by the nature of some Internet-related activities (i.e., rapid switching from one source of information or interactions to another; Wilmer, Sherman, \& Chein, 2017). For example, due to their vulnerability to distraction and impulsivity, people with ADHD may be more attracted to medias involving constant updates, such as social networks (Andreassen et al., 2016), that maintain patterns of inattention. Such hypotheses still need to be assessed in further studies.

The highest contribution of an individual addiction to the variance in the severity of MD and BPD was work addiction. The construct of work addiction remains understudied; however, several studies have identified stressors such as work-related organizational difficulties or perceived effortreward imbalance as possible determinants of work addiction (Andreassen, Schaufeli, \& Pallesen, 2018). The probable association between such stressors and work addiction could partly explain work addiction's contribution to MD. When faced with such stressors, people with work addiction who are trapped by the high importance given to work-related rewards (i.e., the addiction is related to work) are probably prone to making cognitive appraisals, which amplify perceptions of loss in response to those stressors and then this contributes to the greater severity of MD (Beck \& Bredemeier, 2016). Similar comments could be made about the strong associations between work addiction and BPD, although there is probably a more significant contribution from emotion regulation difficulties in the process (Sloan et al., 2017).

\section{Unique versus shared explanation of variance (CA)}

CA revealed which proportions of the total explained variance were unique to each addiction, and how the remaining variance was shared between all the possible combinations of addictions. Overall, between 39.1\% (ADHD) and 51.4\% (MD) of the overall variance explained was due to unique contributions from the 10 addictions. Accordingly, a high proportion of the variance in severity explained was shared between addictions, which reflects the homogeneity within addictions, possibly in part a consequence of the same vulnerabilities or mechanisms underlying these addictions (Kim \& Hodgins, 2018; Shaffer et al., 2004). This is especially apparent in technology-based BAs, which account for most of the variance explained shared within BAs, particularly for SAD, which is associated with a preference for virtual social contacts instead of face-to-face contacts (Sioni et al., 2017). However, BAs had also high shares of unique variance explained, which reflects that there is some remaining heterogeneity between BAs, particularly for work addiction, which is conceptually different as it is related to the work context rather than leisure and has especially high unique associations. Relatively few variance was shared exclusively within SUDs, but a greater proportion was shared between SUDs and BAs. This shows that BAs were not only relevant to MHPs on their own, but also that their frequent co-occurrence with SUDs was 
associated with worse mental health. Co-occurring BAs with SUDs may even partly explain why SUDs are associated with MHPs. These findings provide strong empirical support to earlier recommendations to identify BAs that may accompany SUDs or MHPs to adapt treatment strategies accordingly (Freimuth et al., 2008). Especially in young men, awareness of these issues may be crucial.

\section{Direction of associations}

Although this study only illustrated the associations between addictions and MHPs in one direction, there are several possible explanations for such associations that cannot be tested using a cross-sectional design (for a comprehensive discussion of possible mechanisms, see Lieb, 2015; Schuckit, 2006). First, the presence of addictions, especially multiple addictions, may be a direct cause of MHPs. Second, MHPs may cause vulnerability to multiple addictions. Third, although this is likely to be unsuccessful, a substance or behavior may be used to cope with the symptoms of an MHP, eventually leading the individual to look for relief via yet another substance or behavior. Finally, MHPs and addictions may be primarily the result of other risk factors (the third variable explanation, i.e., socioeconomic stress, family difficulties, personality, transdiagnostic psychopathological dimensions, etc.). All of these explanations may be true to some degree, and they may well interact which each other, i.e., a prior risk factor may increase vulnerability to MHPs as well as to addictions, and MHPs and addictions may later come to reinforce each other. Ecological momentary assessment studies could be helpful to assess such mechanisms (Benarous et al., 2016).

\section{Limitations}

This study had several limitations. First, the sample was restricted to young men, and our results regarding the importance of specific addictions for MHPs may not necessarily generalize to other population groups. For example, young women may be less involved in gaming (Desai, KrishnanSarin, Cavallo, \& Potenza, 2010) and Internet sex (Döring, Daneback, Shaughnessy, Grov, \& Byers, 2017; Luder et al., 2011), but they may also less frequently exhibit SUDs (Brady \& Randall, 1999). This may considerably alter patterns of cooccurring addictions and the degree to which those addictions contribute to MHPs compared to men. Older age groups may also differ considerably from younger age groups with regard to addictive behaviors: they may particularly show less technology-related addictions, but also less often cannabis use disorder and less illicit drug use. However, the overall finding of the importance of co-occurring contributions to MHPs by addictions may very well be generalizable to the general population. Indeed, one of this study's strengths was its non-selective sampling, which has several advantages over the convenience sampling often used in the study of BAs. A second limitation was that our analyses were cross-sectional, therefore limiting any conclusions about the direction of effects. Finally, most of the instruments used in this study were short, self-reported screening measures from different theoretical backgrounds, which do not share a common definition of addiction. Their cut-offs certainly require more validation and the instruments intended to measure addictions as well as MHPs may also identify less severe cases compared with a clinical diagnosis.

\section{CONCLUSIONS}

The 10 addictions measured in this study explained a considerable part of the variance in the severity of four MHPs. BAs explained a higher proportion of the variance in severity than did SUDs, emphasizing the importance of BAs for public health. However, these results need replication in samples with a broader age range that also include women. Further work on the conceptualization and measurement of BAs is also needed before they can be fully included into diagnostic systems (Aarseth et al., 2017; Kardefelt-Winther et al., 2017; Rumpf et al., 2019). Most of the variance in the severities of MHPs could not be explained by individual addictions uniquely, but was shared between addictions, most notably between BAs or shared jointly between BAs and SUDs. Associations between one addiction and an MHP are therefore often in concert with other addictions present. Using a perspective that focuses on the interactions between different addictive behaviors, and possibly additional related variables, may be a promising avenue toward explaining the link between addictions and mental health, rather than focusing on one addiction at a time. A broad range of addictions should be considered when investigating links between addictions and MHPs, and the development of new preventive interventions, harm-reduction strategies, and treatment approaches may be needed for individuals with co-occurring addictions and MHPs. When treating or taking care of individuals with one addiction, it may be relevant to look out for the presence of other addictions, especially also BAs (Freimuth et al., 2008), which, if present, could be associated with MHPs and a more complex overall situation. Holistic treatment approaches, for example, integrated treatment approaches (Dom \& Moggi, 2015; Morisano et al., 2014; van Wamel et al., 2015) considering addictions and MHPs together may be promising for individuals with addictive disorders and co-occurring MHPs (Penzenstadler et al., 2018). The transdiagnostic component model of addiction treatment (Kim \& Hodgins, 2018) targets components common to many, if not all, addictions, and it may also be extended to target components underlying addictions and MHPs, although these components yet need identification or confirmation. Furthermore, mobile health technologies (i.e., smartphone apps) could be promising, especially among younger people, as individuals could be reached at critical moments when they are facing difficulties (Pennou, Lecomte, Potvin, \& Khazaal, 2019). However, defining and assessing how to use such devices to help people with BAs, especially those conveyed by the Internet and smartphones, remains a challenge.

Funding sources: The C-SURF study was funded by the Swiss National Science Foundation (FN 33CSC0_122679, FN 33CS30_139467, and FN 33CS30_148493). 
Authors' contribution: SM, JS, and GG conceived the study. SM conducted the statistical analysis, with support from JS and GG. SM also wrote the initial draft of the manuscript. All authors contributed to data analysis and interpretation and to the writing of the final manuscript. GG obtained funding and supervised the study. All authors had full access to all the study data and take responsibility for data integrity and the accuracy of the data analysis.

Conflict of interest: The authors declare no conflict of interest.

Acknowledgements: The authors would like to thank Céline Gachoud and Christiane Gmel for their valuable work in organizing the study and collecting data.

\section{REFERENCES}

Aarseth, E., Bean, A. M., Boonen, H., Colder Carras, M., Coulson, M., Das, D., Deleuze, J., Dunkels, E., Edman, J., Ferguson, C. J., Haagsma, M. C., Helmersson Bergmark, K., Hussain, Z., Jansz, J., Kardefelt-Winther, D., Kutner, L., Markey, P., Nielsen, R. K., Prause, N., Przybylski, A., Quandt, T., Schimmenti, A., Starcevic, V., Stutman, G., Van Looy, J., \& Van Rooij, A. J. (2017). Scholars' open debate paper on the World Health Organization ICD-11 Gaming Disorder proposal. Journal of Behavioral Addictions, 6(3), 267-270. doi:10.1556/2006.5.2016.088

Adams, S. (2017). Psychopharmacology of tobacco and alcohol comorbidity: A review of current evidence. Current Addiction Reports, 4(1), 25-34. doi:10.1007/s40429-017-0129-z

Adamsom, S. J., \& Sellman, J. D. (2003). A prototype screening instrument for cannabis use disorder: The Cannabis Use Disorders Identification Test (CUDIT) in an alcohol-dependent clinical sample. Drug and Alcohol Review, 22(3), 309-315. doi:10.1080/0959523031000154454

American Psychiatric Association. (2013). Diagnostic and statistical manual of mental disorders (5th ed.). Washington, DC: American Psychiatric Association.

Andreas, J. B., Lauritzen, G., \& Nordfjærn, T. (2015). Cooccurrence between mental distress and poly-drug use: A ten year prospective study of patients from substance abuse treatment. Addictive Behaviors, 48, 71-78. doi:10.1016/j.addbeh. 2015.05.001

Andreassen, C. S., Billieux, J., Griffiths, M. D., Kuss, D. J., Demetrovics, Z., Mazzoni, E., \& Pallesen, S. (2016). The relationship between addictive use of social media and video games and symptoms of psychiatric disorders: A large-scale cross-sectional study. Psychology of Addictive Behaviors, 30(2), 252-262. doi:10.1037/adb0000160

Andreassen, C. S., Griffiths, M. D., Hetland, J., \& Pallesen, S. (2012). Development of a Work Addiction Scale. Scandinavian Journal of Psychology, 53(3), 265-272. doi:10.1111/ j.1467-9450.2012.00947.x

Andreassen, C. S., Schaufeli, W. B., \& Pallesen, S. (2018). Myths about "The myths about work addiction". Commentary on: Ten myths about work addiction (Griffiths et al., 2018). Journal of Behavioral Addictions, 7(4), 858-862. doi:10.1556/2006.7. 2018.126
Annaheim, B., Scotto, T. J., \& Gmel, G. (2010). Revising the Cannabis Use Disorders Identification Test (CUDIT) by means of item response theory. International Journal of Methods in Psychiatric Research, 19(3), 142-155. doi:10.1002/mpr.308

Bantin, T., Stevens, S., Gerlach, A. L., \& Hermann, C. (2016). What does the facial dot-probe task tell us about attentional processes in social anxiety? A systematic review. Journal of Behavior Therapy and Experimental Psychiatry, 50, 40-51. doi:10.1016/j.jbtep.2015.04.009

Bech, P., Rasmussen, N. A., Olsen, L. R., Noerholm, V., \& Abildgaard, W. (2001). The sensitivity and specificity of the Major Depression Inventory, using the Present State Examination as the index of diagnostic validity. Journal of Affective Disorders, 66(2-3), 159-164. doi:10.1016/S0165-0327(00) 00309-8

Bech, P., Timmerby, N., Martiny, K., Lunde, M., \& Soendergaard, S. (2015). Psychometric evaluation of the Major Depression Inventory (MDI) as depression severity scale using the LEAD (Longitudinal Expert Assessment of All Data) as index of validity. BMC Psychiatry, 15(1), 190. doi:10.1186/s12888015-0529-3

Beck, A. T., \& Bredemeier, K. (2016). A unified model of depression: Integrating clinical, cognitive, biological, and evolutionary perspectives. Clinical Psychological Science, 4(4), 596-619. doi:10.1177/2167702616628523

Benarous, X., Edel, Y., Consoli, A., Brunelle, J., Etter, J.-F., Cohen, D., \& Khazaal, Y. (2016). Ecological momentary assessment and smartphone application intervention in adolescents with substance use and comorbid severe psychiatric disorders: Study protocol. Frontiers in Psychiatry, 7, 157. doi:10.3389/fpsyt.2016.00157

Bhalla, I. P., Stefanovics, E. A., \& Rosenheck, R. A. (2017). Clinical epidemiology of single versus multiple substance use disorders: Polysubstance use disorder. Medical Care, 55, S24-S32. doi:10.1097/MLR.0000000000000731

Booth, B. M., Curran, G., Han, X., Wright, P., Frith, S., Leukefeld, C., Falck, R., \& Carlson, R. G. (2010). Longitudinal relationship between psychological distress and multiple substance use: Results from a three-year multisite natural-history study of rural stimulant users. Journal of Studies on Alcohol and Drugs, 71(2), 258-267. doi:10.15288/jsad.2010.71.258

Brady, K. T., \& Randall, C. L. (1999). Gender differences in substance use disorders. Psychiatric Clinics of North America, 22(2), 241-252. doi:10.1016/S0193-953X(05)70074-5

Brook, J. S., Zhang, C., Rubenstone E., Primack, B. A., \& Brook, D. W. (2016). Comorbid trajectories of substance use as predictors of antisocial personality disorder, major depressive episode, and generalized anxiety disorder. Addictive Behaviors, 62, 114-121. doi:10.1016/j.addbeh.2016.06.003

Carnes, P. J., Delmonico, D. L., \& Griffin, E. (2009). In the shadows of the net: Breaking free of compulsive online sexual behavior. New York, NY: Simon and Schuster.

Chow, C. M., Wieman, D., Cichocki, B., Qvicklund, H., \& Hiersteiner, D. (2013). Mission impossible: Treating serious mental illness and substance use co-occurring disorder with integrated treatment: A meta-analysis. Mental Health and Substance Use, 6(2), 150-168. doi:10.1080/17523281.2012. 693130

Cohen, J. (1988). Statistical power analysis for the behavioral sciences (2nd ed.). Hillsdale, NJ: Lawrence Erlbaum Associates. 
Cohen, J., Cohen, P., West, S. G., \& Aiken, L. S. (2003). Applied multiple regression/correlation analysis for the behavioral sciences (3rd ed.). Mahwah, NJ: Lawrence Erlbaum Associates.

Connor, J. P., Gullo, M. J., Chan, G., Young, R. M., Hall, W. D., \& Feeney, G. F. (2013). Polysubstance use in cannabis users referred for treatment: Drug use profiles, psychiatric comorbidity and cannabis-related beliefs. Frontiers in Psychiatry, 4, 79. doi:10.3389/fpsyt.2013.00079

Dalrymple, K., Martinez, J., Tepe, E., Young, D., Chelminski, I., Morgan, T., \& Zimmerman, M. (2013). A clinically useful Social Anxiety Disorder Outcome Scale. Comprehensive Psychiatry, 54(7), 758-765. doi:10.1016/j.comppsych.2013.02.006

Delmonico, D., \& Miller, J. (2003). The Internet Sex Screening Test: A comparison of sexual compulsives versus non-sexual compulsives. Sexual and Relationship Therapy, 18(3), 261-276. doi:10.1080/1468199031000153900

Desai, R. A., Krishnan-Sarin, S., Cavallo, D., \& Potenza, M. N. (2010). Video-gaming among high school students: Health correlates, gender differences, and problematic gaming. Pediatrics, 126(6), e1414-e1424. doi:10.1542/peds.2009-2706

Dom, G., \& Moggi, F. (2015). Toward a new model of care: Integrating mental health, substance use, and somatic care. In G. Dom \& F. Moggi (Eds.), Co-occurring addictive and psychiatric disorders (pp. 375-389). Berlin, Germany: Springer.

Dom, G., \& Moggi, F. (2016). Co-occurring addictive and psychiatric disorders. Berlin, Germany: Springer.

Dong, G., \& Potenza, M. N. (2016). Risk-taking and risky decision-making in Internet gaming disorder: Implications regarding online gaming in the setting of negative consequences. Journal of Psychiatric Research, 73, 1-8. doi:10.1016/j.jpsychires.2015.11.011

Döring, N., Daneback, K., Shaughnessy, K., Grov, C., \& Byers, E. S. (2017). Online sexual activity experiences among college students: A four-country comparison. Archives of Sexual Behavior, 46(6), 1641-1652. doi:10.1007/s10508-015-0656-4

Dufour, M., Brunelle, N., Tremblay, J., Leclerc, D., Cousineau, M.-M., Khazaal, Y., Légaré, A. A., Rousseau, M., \& Berbiche, D. (2016). Gender difference in Internet use and Internet problems among Quebec high school students. The Canadian Journal of Psychiatry, 61(10), 663-668. doi:10.1177/ 0706743716640755

Evren, B., Evren, C., Dalbudak, E., Topcu, M., \& Kutlu, N. (2018). Relationship of Internet addiction severity with probable ADHD and difficulties in emotion regulation among young adults. Psychiatry Research, 269, 494-500. doi:10.1016/ j.psychres.2018.08.112

Fagerstrom, K. O., Heatherton, T. F., \& Kozlowski, L. (1992). Nicotine addiction and its assessment. Ear, Nose \& Throat Journal, 69(11), 763-767.

Franc, E., Khazaal, Y., Jasiowka, K., Lepers, T., BianchiDemicheli, F., \& Rothen, S. (2018). Factor structure of the Cybersex Motives Questionnaire. Journal of Behavioral Addictions, 7(3), 601-609. doi:10.1556/2006.7.2018.67

Freimuth, M., Waddell, M., Stannard, J., Kelley, S., Kipper, A., Richardson, A., \& Szuromi, I. (2008). Expanding the scope of dual diagnosis and co-addictions: Behavioral addictions. Journal of Groups in Addiction \& Recovery, 3(3-4), 137-160. doi:10.1080/15560350802424944

Gmel, G., Akre, C., Astudillo, M., Bähler, C., Baggio, S., Bertholet, N., Clair, C., Cornuz, J., Daeppen, J.-B., Deline, S., Dermota, P.,
Dey, M., Dupuis, M., Estévez, N., Foster, S., Gaume, J., Haug, S., Henchoz, Y., Kuendig, H., Mohler-Kuo, M., N'Goran, A., Schaub, M., Studer, J., Suris, J.-C., \& Wang, J. (2015). The Swiss Cohort Study on substance use risk factors - Findings of two waves. Sucht, 61(4), 251-262. doi:10.1024/0939-5911. a000380

Grant, B. F., Dawson, D. A., Stinson, F. S., Chou, P. S., Kay, W., \& Pickering, R. (2003). The Alcohol Use Disorder and Associated Disabilities Interview Schedule-IV (AUDADIS-IV): Reliability of alcohol consumption, tobacco use, family history of depression and psychiatric diagnostic modules in a general population sample. Drug and Alcohol Dependence, 71(1), 7-16. doi:10.1016/S0376-8716(03)00070-X

Grant, J. E., Potenza, M. N., Weinstein, A., \& Gorelick, D. A. (2010). Introduction to behavioral addictions. The American Journal of Drug and Alcohol Abuse, 36(5), 233-241. doi:10.3109/00952990.2010.491884

Haug, S., Paz Castro, R., Kwon, M., Filler, A., Kowatsch, T., \& Schaub, M. P. (2015). Smartphone use and smartphone addiction among young people in Switzerland. Journal of Behavioral Addictions, 4(4), 299-307. doi:10.1556/2006.4.2015.037

Heatherton, T. F., Kozlowski, L. T., Frecker, R. C., \& Fagerstrom, K.-O. (1991). The Fagerström Test for Nicotine Dependence: A revision of the Fagerstrom Tolerance Questionnaire. British Journal of Addiction, 86(9), 1119-1127. doi:10.1111/j.13600443.1991.tb01879.x

Heeren, A., \& McNally, R. J. (2016). An integrative network approach to social anxiety disorder: The complex dynamic interplay among attentional bias for threat, attentional control, and symptoms. Journal of Anxiety Disorders, 42, 95-104. doi:10.1016/j.janxdis.2016.06.009

Kardefelt-Winther, D., Heeren, A., Schimmenti, A., van Rooij, A., Maurage, P., Carras, M., Edman, J., Blaszczynski, A., Khazaal, Y., \& Billieux, J. (2017). How can we conceptualize behavioural addiction without pathologizing common behaviours? Addiction, 112(10), 1709-1715. doi:10.1111/add.13763

Kessler, R. C., Adler, L., Ames, M., Demler, O., Faraone, S., Hiripi, E., Howes, M. J., Jin, R., Secnik, K., Spencer, T., Ustun, T. B., \& Walters, E. E. (2005). The World Health Organization Adult ADHD Self-Report Scale (ASRS): A short screening scale for use in the general population. Psychological Medicine, 35(02), 245-256. doi:10.1017/S0033291704002892

Khazaal, Y., Van Singer, M., Chatton, A., Achab, S., Zullino, D., Rothen, S., Khan, R., Billieux, J., \& Thorens, G. (2014). Does self-selection affect samples' representativeness in online surveys? An investigation in online video game research. Journal of Medical Internet Research, 16(7), e164. doi:10.2196/ jmir.2759

Kim, H. S., \& Hodgins, D. C. (2018). Component model of addiction treatment: A pragmatic transdiagnostic treatment model of behavioral and substance addictions. Frontiers in Psychiatry, 9. doi:10.3389/fpsyt.2018.00406

King, D. L., Delfabbro, P. H., Potenza, M. N., Demetrovics, Z., Billieux, J., \& Brand, M. (2018). Internet gaming disorder should qualify as a mental disorder. Australian \& New Zealand Journal of Psychiatry, 52(7), 615-617. doi:10.1177/ 0004867418771189

Knight, J. R., Wechsler, H., Kuo, M., Seibring, M., Weitzman, E. R., \& Schuckit, M. A. (2002). Alcohol abuse and dependence among U.S. college students. Journal of Studies on Alcohol, 63(3), 263-270. doi:10.15288/jsa.2002.63.263 
Konkolÿ Thege, B., Hodgins, D. C., \& Wild, T. C. (2016). Cooccurring substance-related and behavioral addiction problems: A person-centered, lay epidemiology approach. Journal of Behavioral Addictions, 5(4), 614-622. doi:10.1556/2006.5. 2016.079

Kwon, M., Kim, D.-J., Cho, H., \& Yang, S. (2014). The Smartphone Addiction Scale: Development and validation of a short version for adolescents. PLoS One, 8(12), e83558. doi:10.1371/journal.pone.0083558

Leeman, R. F., \& Potenza, M. N. (2013). A targeted review of the neurobiology and genetics of behavioural addictions: An emerging area of research. The Canadian Journal of Psychiatry, 58(5), 260-273. doi:10.1177/070674371305800503

Lemmens, J. S., Valkenburg, P. M., \& Peter, J. (2009). Development and validation of a Game Addiction Scale for adolescents. Media Psychology, 12(1), 77-95. doi:10.1080/15213260 802669458

Lenz, A. S., Henesy, R., \& Callender, K. (2016). Effectiveness of seeking safety for co-occurring posttraumatic stress disorder and substance use. Journal of Counseling \& Development, 94(1), 51-61. doi:10.1002/jcad.12061

Lieb, R. (2015). Epidemiological perspectives on comorbidity between substance use disorders and other mental disorders. In G. Dom \& F. Moggi (Eds.), Co-occurring addictive and psychiatric disorders (pp. 3-12). Berlin, Germany: Springer.

Luder, M.-T., Pittet, I., Berchtold, A., Akré, C., Michaud, P.-A., \& Surís, J.-C. (2011). Associations between online pornography and sexual behavior among adolescents: Myth or reality? Archives of Sexual Behavior, 40(5), 1027-1035. doi:10.1007/ s10508-010-9714-0

MacLean, R. R., Sofuoglu, M., \& Rosenheck, R. (2018). Tobacco and alcohol use disorders: Evaluating multimorbidity. Addictive Behaviors, 78, 59-66. doi:10.1016/j.addbeh.2017. 11.006

Marmet, S., Studer, J., Bertholet, N., Grazioli, V. S., Daeppen, J. B., \& Gmel, G. (2019). Interpretation of DSM-5 alcohol use disorder criteria in self-report surveys may change with age. A longitudinal analysis of young Swiss men. Addiction Research \& Theory, 27(6), 489-497. doi:10.1080/16066359.2018. 1547817

Marmet, S., Studer, J., Rougemont-Bücking, A., \& Gmel, G. (2018). Latent profiles of family background, personality and mental health factors and their association with behavioural addictions and substance use disorders in young Swiss men. European Psychiatry, 52, 76-84. doi:10.1016/j.eurpsy.2018. 04.003

Meerkerk, G. J., van den Eijnden, R. J., Franken, I., \& Garretsen, H. (2010). Is compulsive Internet use related to sensitivity to reward and punishment, and impulsivity? Computers in Human Behavior, 26(4), 729-735. doi:10.1016/j.chb.2010. 01.009

Meerkerk, G. J., Van Den Eijnden, R. J. J. M., Vermulst, A. A., \& Garretsen, H. F. L. (2009). The Compulsive Internet Use Scale (CIUS): Some psychometric properties. CyberPsychology \& Behavior, 12(1), 1-6. doi:10.1089/cpb.2008.0181

Melartin, T., Häkkinen, M., Koivisto, M., Suominen, K., \& Isometsä, E. (2009). Screening of psychiatric outpatients for borderline personality disorder with the McLean Screening Instrument for Borderline Personality Disorder (MSI-BPD). Nordic Journal of Psychiatry, 63(6), 475-479. doi:10.3109/ 08039480903062968
Morisano, D., Babor, T. F., \& Robaina, K. A. (2014). Cooccurrence of substance use disorders with other psychiatric disorders: Implications for treatment services. Nordic Studies on Alcohol and Drugs, 31(1), 5-25. doi:10.2478/nsad-20140002

Moss, H. B., Goldstein, R. B., Chen, C. M., \& Yi, H.-Y. (2015). Patterns of use of other drugs among those with alcohol dependence: Associations with drinking behavior and psychopathology. Addictive Behaviors, 50, 192-198. doi:10.1016/ j.addbeh.2015.06.041

Nimon, K. F., \& Oswald, F. L. (2013). Understanding the results of multiple linear regression: Beyond standardized regression coefficients. Organizational Research Methods, 16(4), 650-674. doi:10.1177/1094428113493929

Odlaug, B. L., Stinchfield, R., Golberstein, E., \& Grant, J. E. (2013). The relationship of tobacco use with gambling problem severity and gambling treatment outcome. Psychology of Addictive Behaviors, 27(3), 696-704. doi:10.1037/a0029812

Office of Alcoholism and Substance Abuse Services. (n.d.). DSM-IV pathological gambling diagnostic form. Retrieved from http:// www.oasas.ny.gov/gambling/documents/822dsmivforweb.pdf

Paik, S. H., Park, C.-H., Kim, J.-Y., Chun, J.-W., Choi, J.-S., \& Kim, D.-J. (2019). Prolonged bedtime smartphone use is associated with altered resting-state functional connectivity of the insula in adult smartphone users. Frontiers in Psychiatry, 10, 516. doi:10.3389/fpsyt.2019.00516

Panova, T., \& Carbonell, X. (2018). Is smartphone addiction really an addiction? Journal of Behavioral Addictions, 7(2), 252-259. doi:10.1556/2006.7.2018.49

Pennou, A., Lecomte, T., Potvin, S., \& Khazaal, Y. (2019). Mobile intervention for individuals with psychosis and comorbid substance use disorder: A literature review. Frontiers in Psychiatry, 10, 302. doi:10.3389/fpsyt.2019.00302

Penzenstadler, L., Kolly, S., Rothen, S., Khazaal, Y., \& Kramer, U. (2018). Effects of substance use disorder on treatment process and outcome in a ten-session psychiatric treatment for borderline personality disorder. Substance Abuse Treatment, Prevention, and Policy, 13(1), 10. doi:10.1186/s13011-0180145-6

R Core Team. (2013). R: A language and environment for statistical computing. Vienna, Austria: R Core Team.

Ray-Mukherjee, J., Nimon, K., Mukherjee, S., Morris, D. W., Slotow, R., \& Hamer, M. (2014). Using commonality analysis in multiple regressions: A tool to decompose regression effects in the face of multicollinearity. Methods in Ecology and Evolution, 5(4), 320-328. doi:10.1111/2041210X.12166

Rumpf, H.-J., Brandt, D., Demetrovics, Z., Billieux, J., Carragher, N., Brand, M., Bowden-Jones, H., Rahimi-Movaghar, A., Assanangkornchai, S., Glavak-Tkalic, R., Borges, G., Lee, H. K., Rehbein, F., Fineberg, N., Mann, K., Potenza, M., Stein, D. J., Higuchi, S., King, D., Saunders, J. B., \& Poznyak, V. (2019). Epidemiological challenges in the study of behavioral addictions: A call for high standard methodologies. Current Addiction Reports, 6(3), 331-337. doi:10.1007/ s40429-019-00262-2

Schluter, M. G., Hodgins, D. C., Wolfe, J., \& Wild, T. C. (2018). Can one simple questionnaire assess substance-related and behavioural addiction problems? Results of a proposed new screener for community epidemiology. Addiction, 113(8), 1528-1537. doi:10.1111/add.14166 
Schuckit, M. A. (2006). Comorbidity between substance use disorders and psychiatric conditions. Addiction, 101(s1), 76-88. doi:10.1111/j.1360-0443.2006.01592.x

Seibold, D. R., \& McPhee, R. D. (1979). Commonality analysis: A method for decomposing explained variance in multiple regression analyses. Human Communication Research, 5(4), 355-365. doi:10.1111/j.1468-2958.1979.tb00649.x

Shaffer, H. J., LaPlante, D. A., LaBrie, R. A., Kidman, R. C., Donato, A. N., \& Stanton, M. V. (2004). Toward a syndrome model of addiction: Multiple expressions, common etiology. Harvard Review of Psychiatry, 12(6), 367-374. doi:10.1080/ 10673220490905705

Sioni, S. R., Burleson, M. H., \& Bekerian, D. A. (2017). Internet gaming disorder: Social phobia and identifying with your virtual self. Computers in Human Behavior, 71, 11-15. doi:10.1016/j.chb.2017.01.044

Skinstad, A. H., \& Swain, A. (2001). Comorbidity in a clinical sample of substance abusers. The American Journal of Drug and Alcohol Abuse, 27(1), 45-64. doi:10.1081/ADA100103118

Sloan, E., Hall, K., Moulding, R., Bryce, S., Mildred, H., \& Staiger, P. K. (2017). Emotion regulation as a transdiagnostic treatment construct across anxiety, depression, substance, eating and borderline personality disorders: A systematic review. Clinical Psychology Review, 57, 141-163. doi:10.1016/ j.cpr.2017.09.002

Slutske, W. S., Eisen, S., True, W. R., Lyons, M. J., Goldberg, J., \& Tsuang, M. (2000). Common genetic vulnerability for pathological gambling and alcohol dependence in men. Archives of General Psychiatry, 57(7), 666-673. doi:10.1001/archpsyc. 57.7.666

Slutske, W. S., Ellingson, J. M., Richmond-Rakerd, L. S., Zhu, G., \& Martin, N. G. (2013). Shared genetic vulnerability for disordered gambling and alcohol use disorder in men and women: Evidence from a national community-based Australian Twin Study. Twin Research and Human Genetics, 16(2), 525-534. doi:10.1017/thg.2013.11

Smith, G. W., Farrell, M., Bunting, B. P., Houston, J. E., \& Shevlin, M. (2011). Patterns of polydrug use in Great Britain: Findings from a national household population survey. Drug and Alcohol Dependence, 113(2-3), 222-228. doi:10.1016/j.drugalcdep. 2010.08.010

Starcevic, V. (2016). Behavioural addictions: A challenge for psychopathology and psychiatric nosology. Australian \& New Zealand Journal of Psychiatry, 50(8), 721-725. doi:10.1177/ 0004867416654009

Starcevic, V., \& Khazaal, Y. (2017). Relationships between behavioural addictions and psychiatric disorders: What is known and what is yet to be learned? Frontiers in Psychiatry, 8, 53. doi:10.3389/fpsyt.2017.00053

Studer, J., Baggio, S., Mohler-Kuo, M., Dermota, P., Gaume, J., Bertholet, N., Daeppen, J. B., \& Gmel, G. (2013). Examining non-response bias in substance use research - Are late respondents proxies for non-respondents? Drug and Alcohol Dependence, 132(1-2), 316-323. doi:10.1016/j.drugalcdep.2013. 02.029

Sussman, S., Arpawong, T. E., Sun, P., Tsai, J., Rohrbach, L. A., \& Spruijt-Metz, D. (2014). Prevalence and co-occurrence of addictive behaviors among former alternative high school youth. Journal of Behavioral Addictions, 3(1), 33-40. doi:10.1556/ JBA.3.2014.005
Sussman, S., Lisha, N., \& Griffiths, M. (2011). Prevalence of the addictions: A problem of the majority or the minority? Evaluation \& the Health Professions, 34(1), 3-56. doi:10.1177/ 0163278710380124

Torrens, M., \& Rossi, P. (2015). Mood disorders and addiction. In G. Dom \& F. Moggi (Eds.), Co-occurring addictive and psychiatric disorders: A practice-based handbook from a European perspective (pp. 103-117). Berlin, Heidelberg, Germany: Springer.

True, W. R., Xian, H., Scherrer, J. F., Madden, P. A., Bucholz, K. K., Heath, A. C., Eisen, S. A., Lyons, M. J., Goldberg, J., \& Tsuang, M. (1999). Common genetic vulnerability for nicotine and alcohol dependence in men. Archives of General Psychiatry, 56(7), 655-661. doi:10.1001/archpsyc.56.7.655

Vaccaro, A. G., \& Potenza, M. N. (2019). Diagnostic and classification considerations regarding gaming disorder: Neurocognitive and neurobiological features. Frontiers in Psychiatry, 10, 405. doi:10.3389/fpsyt.2019.00405

van Emmerik-van Oortmerssen, K., Konstenius, M., \& Schoevers, R. A. (2015). ADHD and addiction. In G. Dom \& F. Moggi (Eds.), Co-occurring addictive and psychiatric disorders: A practice-based handbook from a European perspective (pp. 179-191). Berlin, Heidelberg, Germany: Springer.

van Wamel, A., van Rooijen, S., \& Kroon, H. (2015). Integrated treatment: The model and European experiences. In G. Dom \& F. Moggi (Eds.), Co-occurring addictive and psychiatric disorders (pp. 27-45). Berlin, Germany: Springer.

Varfi, N., Rothen, S., Jasiowka, K., Lepers, T., Bianchi-Demicheli, F., \& Khazaal, Y. (2019). Sexual desire, mood, attachment style, impulsivity, and self-esteem as predictive factors for addictive cybersex. JMIR Mental Health, 6(1), e9978. doi:10.2196/mental.9978

Walter, M. (2015). Personality disorder and addiction. In G. Dom \& F. Moggi (Eds.), Co-occurring addictive and psychiatric disorders: A practice-based handbook from a European perspective (pp. 137-148). Berlin, Heidelberg, Germany: Springer.

Weinstein, A., Dorani, D., Elhadif, R., Bukovza, Y., Yarmulnik, A., \& Dannon, P. (2015). Internet addiction is associated with social anxiety in young adults. Annals of Clinical Psychiatry, 27(1), 4-9.

White, A., Chan, G. C., Quek, L.-H., Connor, J. P., Saunders, J. B., Baker, P., Brackenridge, C., \& Kelly, A. B. (2013). The topography of multiple drug use among adolescent Australians: Findings from the National Drug Strategy Household Survey. Addictive Behaviors, 38(4), 2068-2073. doi:10.1016/j.addbeh. 2013.01.001

Wilmer, H. H., Sherman, L. E., \& Chein, J. M. (2017). Smartphones and cognition: A review of research exploring the links between mobile technology habits and cognitive functioning. Frontiers in Psychology, 8, 605. doi:10.3389/ fpsyg.2017.00605

Zanarini, M. C., Vujanovic, A. A., Parachini, E. A., Boulanger, J. L., Frankenburg, F. R., \& Hennen, J. (2003). A screening measure for BPD: The McLean screening instrument for borderline personality disorder (MSI-BPD). Journal of Personality Disorders, 17(6), 568-573. doi:10.1521/pedi.17.6. 568.25355

Zlot, Y., Goldstein, M., Cohen, K., \& Weinstein, A. (2018). Online dating is associated with sex addiction and social anxiety. Journal of Behavioral Addictions, 7(3), 821-826. doi:10.1556/ 2006.7.2018.66 